\title{
On the Paradox of the Duality of Autoregressive and Moving Average Processes
}

\author{
Elechi Onyemachi, Iheanyi Sylvester Iwueze, Eleazar Chukwunenye Nwogu \\ Department of Statistics, Federal University of Technology, Owerri, Nigeria \\ Email: elesuccess@yahoo.com, isiwueze@yahoo.com,nwoguec@yahoo.com
}

How to cite this paper: Onyemachi, E., Iwueze, I.S. and Nwogu, E.C. (2022) On the Paradox of the Duality of Autoregressive and Moving Average Processes. Journal of Applied Mathematics and Physics, 10, 589609.

https://doi.org/10.4236/jamp.2022.102043

Received: March 18, 2021

Accepted: February 25, 2022

Published: February 28, 2022

Copyright $\odot 2022$ by author(s) and Scientific Research Publishing Inc. This work is licensed under the Creative Commons Attribution International License (CC BY 4.0).

http://creativecommons.org/licenses/by/4.0/

\begin{abstract}
A widely held view in time series analysis is the concept of duality that a finite order stationary autoregressive process of order $p(\operatorname{AR}(p))$ is equivalent to an infinite order moving average (MA) process and a finite order invertible moving average of order $q(\mathrm{MA}(q))$ is equivalent to an infinite order autoregressive (AR) process. The purpose of this paper is to demonstrate that the concept is not universally true. Thus, a finite order stationary autoregressive process of order $\mathrm{p}(\operatorname{AR}(p))$ can be written as an finite order moving average process and a finite order moving average process of order $q(\mathrm{MA}(q))$ can be written as a finite order stationary autoregressive process. The regions of breakdown of concept of duality were determined for $p=q=1,2$ using method of moments. The method involves equating non-zero autocovariances of the stationary $\operatorname{AR}(p)$ to the equivalent non-zero autocovariances of the invertible $\operatorname{MA}(p)$ to determine the region of non-duality. In such region of breakdown in duality, 1) both the Autocorrelation function and the Partial Autocorrelation function of the AR process and MA process cuts off after equal lags 2) a finite AR model can be adequately represented by a finite MA model of equal order and conversely with the same error variance and 3 ) negative values of the parameters of the AR process are equal in magnitude but opposite in direction to the parameters of the equivalent MA process and conversely. Empirical examples (simulation and real life examples) were used to illustrate these. Therefore, it has been recommended that caution should be exercised in using the concept of duality in time series analysis until future research proves otherwise.
\end{abstract}

\section{Keywords}

Duality, Non-Duality, Method of Moments, Quadratic Inequality, Stationarity Region, Invertibility Region 


\section{Introduction}

The concept of duality is an old topic and a fruitful idea that can be found in many areas of Mathematics and other related disciplines [1] [2] [3]. Duality is a principle that gives two different points of view to the same object [1] [4] [5]. These points of view constitute an instance of opposition or contrast between concepts that are interchangeable, such that all results in one formulation also hold in the dual formulation [6]-[11]. As a consequence, the concept of duality involves symmetry within a system such that a theorem remains valid if certain objects, relations or operations are interchanged [12].

In a mathematical system, the concept of duality forms bases for describing and identifying the property of algebraic structures, theorems and/or expressions, being dual to each other. In his views, [13] stated that the concept of duality involves two objects plus a relation between them that is symmetric, such that one can get from one object to the other and vice versa. Some examples where the principle of duality applies in Mathematics include the linear duality in plane geometry and linear algebra, duality for Abelian groups and Non-Abelian groups, duality for non-linear geometry and Fourier theory, etc. [1]. Similarly, in Physics, the concept of duality has been applied to describe and identify the properties of variables in space. These include mirror symmetry, position momentum, quantum mechanics and electromagnetism [1] [6] [14].

Dual Aspect Concept, also known as Duality Principle, is a fundamental convention of accounting that forms basis for double entry accounting system. Under the accounting system, transactions are classified into debit or credit, loss or profit, etc. which enables every transaction to have dual effects [15] [16]. These dual effects ensure that all aspects of a transaction are accounted for in the financial statements.

In Statistics duality has been used to describe the relationship between models for two classes of stationary time series (the autoregressive and moving average processes). A given stationary autoregressive process of order $p(\operatorname{AR}(p))$ was denoted by [17];

$$
\boldsymbol{\varphi}_{p}(B) X_{t}=e_{t}
$$

we can write (1.1) as

$$
X_{t}=\psi(B) e_{t}
$$

such that

$$
\boldsymbol{\varphi}_{p}(B) \boldsymbol{\psi}(B)=1
$$

In (1.1) and (1.2), $e_{t} \sim N\left(0, \sigma^{2}\right)$ and

$$
\begin{gathered}
\boldsymbol{\varphi}_{p}(B)=1+\phi_{1} B+\phi_{2} B^{2}+\cdots+\phi_{p} B^{p} \\
\psi(B)=1+\psi_{1} B^{1}+\psi_{2} B^{2}+\cdots
\end{gathered}
$$

That is, a finite order stationary AR process (1.1) is equivalent to an infinite order moving average process (1.2). 
Conversely, for a given invertible moving average process of order $q$, $(\mathrm{MA}(q))$ denoted by

$$
X_{t}=\boldsymbol{\theta}_{q}(B) e_{t}
$$

we can write (1.6) as

$$
e_{t}=\boldsymbol{\theta}_{q}^{-1}(B) X_{t}=\Pi(B) X_{t}
$$

such that

$$
\boldsymbol{\theta}_{q}(B) \Pi(B)=1
$$

In (1.6) and (1.7), $e_{t} \sim N\left(0, \sigma^{2}\right)$ and

$$
\begin{gathered}
\boldsymbol{\theta}_{q}(B)=1+\theta_{1} B^{1}+\theta_{2} B^{2}+\cdots+\theta_{q} B^{q} \\
\prod(B)=1+\pi_{1} B^{1}+\pi_{2} B^{2}+\cdots
\end{gathered}
$$

is an infinite but converging series. That is, a finite order invertible MA process (1.6) is equivalent to an infinite order AR process (1.7).

The dual relationship also exists in their autocorrelation functions (ACFs) and partial autocorrelation functions (PACFs) [17]. For an $\operatorname{AR}(p)$ process, while the ACF tails off, the PACF cuts off after lag $\mathrm{p}$, but for $\mathrm{MA}(q)$ process, the ACF cuts off after lag q while the PACF tails off.

The works of [18]-[27] outlined other properties of the duality principle among these models. Using the duality principle, [28] showed that if AR and MA processes of the same order are simulated from the same sequence of errors using the same parameter values, then to a close approximation, the least squares estimates calculated from the MA series will tend to underestimate the true parameter values while those from $A R$ series will tend to over-estimate them by the same amount. Thus, suggesting that the duality principle between $\operatorname{AR}(p)$ is equivalent to an infinite order moving average (MA) process and $\mathrm{MA}(q)$ processes is equivalent to an infinite order autoregressive (AR) process may be universally true.

However, certain real life examples have shown that this principle may not be strictly true. Thereby raising some doubts about the universality of duality in time series analysis. The question that we now ask is, "Is the duality between models for stationary $\operatorname{AR}(p)$ and invertible $\operatorname{MA}(q)$ processes universally true? If not, under what condition(s) will the principle break down? This question is what this study intends to address. Therefore, the ultimate objective of this study is to determine the parameter region within which the principle of duality between models for stationary $\operatorname{AR}(p)$ and invertible $\operatorname{MA}(q)$ processes breaks down. This region has been designated as the 'Non-Duality' region in this study. For the translation from stationary $\operatorname{AR}(p)$ process to invertible $\mathrm{MA}(p)$ process and, from invertible $\mathrm{MA}(p)$ process to stationary $\operatorname{AR}(p)$ process, the method adopted to determine the non-duality region was discussed in Section 2. In Section 3, the study illustrated the breakdown in duality principle between stationary $\operatorname{AR}(p)$ and invertible $\operatorname{MA}(p)$ processes using empirical examples (real life data and simulated series examples) while Section 4 is the concluding remark. 


\section{Methodology}

The methodology adopted to determine the Non-Duality region is the method of moments. The method involves equating non-zero autocovariances of the stationary Autoregressive Process of order $p(\operatorname{AR}(p))$, to corresponding non-zero autocovariances of the invertible Moving Average Process of order $p(\operatorname{MA}(p))$. This is because as noted by [17], the dual relationship between models for stationary $\operatorname{AR}(p)$ and invertible $\operatorname{MA}(q)$ processes also exists between the autocorrelation functions (ACFs) and partial autocorrelation functions (PACFs). For a given sequence of errors, our bases for determining breakdown in duality is to evaluate

$$
\left|R^{\mathrm{AR}(p)}(k)-R^{\mathrm{MA}(p)}(k)\right|=h_{k}, k=0,1, \cdots, p
$$

where $R^{\operatorname{AR}(p)}(k)$ is the lag $k$ autocovariance of the stationary $\operatorname{AR}(p)$ process, $R^{\mathrm{MA}(p)}(k)$ is the lag $k$ autocovariance of the invertible $\mathrm{MA}(p)$ process and $h_{k}$ is the degree of precision. The principle of duality is considered to have broken down if $h_{k} \approx 0 \quad \forall k$ to some degree of approximation. The parameters of stationary $\operatorname{AR}(p)$ process and invertible $\operatorname{MA}(p)$ process for which $h_{k} \approx 0$ give the region where duality breaks down (Non-duality region). Hence, for various degrees of approximations allowable for $h_{k}$, the real values of the parameters for the Non-Duality region are determined.

\subsection{Non-Duality between AR(1) and MA(1) Processes}

For the model and autocovariances of stationary autoregressive process of order one $(\operatorname{AR}(1))[20]$ :

$$
\begin{aligned}
\tilde{X}_{t}=\phi_{1} \tilde{X}_{t-1}+e_{t} ; e_{t} \sim N\left(0, \sigma^{2}\right),-1<\phi_{1}<1 \\
R^{\operatorname{AR}(1)}(k)=\left\{\begin{array}{l}
\frac{\sigma^{2}}{1-\phi_{1}^{2}}, k=0 \\
\frac{\phi_{1} \sigma^{2}}{1-\phi_{1}^{2}}, k=1 \\
\phi_{1} R(k-1), k>1
\end{array}\right.
\end{aligned}
$$

and for invertible moving average process of order one (MA(1)) [20]:

$$
\begin{gathered}
\tilde{X}_{t}=e_{t}-\theta_{1} e_{t-1} ; e_{t} \sim N\left(0, \sigma^{2}\right), \tilde{X}_{t}=X_{t}-\mu,-1<\theta_{1}<1 \\
R^{\operatorname{MA}(1)}(k)=\left\{\begin{array}{l}
\sigma^{2}\left(1+\theta_{1}^{2}\right), k=0 \\
-\theta_{1} \sigma^{2}, k=1 \\
0, k>1
\end{array}\right.
\end{gathered}
$$

where $\tilde{X}_{t}=X_{t}-\mu$ and $\mu=E\left(X_{t}\right)$. By equating non-zero autocovariances of $\operatorname{AR}(p)$ and $\operatorname{MA}(p)$ processes: $p=1$, we obtain

$$
\frac{\sigma^{2}}{1-\phi_{1}^{2}}=\sigma^{2}\left(1+\theta_{1}^{2}\right)
$$




$$
\frac{\phi_{1} \sigma^{2}}{1-\phi_{1}^{2}}=-\theta_{1} \sigma^{2}
$$

By combining (2.6) and (2.7), we obtain

$$
\phi_{1}=\frac{-\theta_{1}}{1+\theta_{1}^{2}} \Rightarrow \phi_{1} \theta_{1}^{2}+\theta_{1}+\phi_{1}=0
$$

Note that for invertible $\mathrm{MA}(1)$ process, the autocorrelation function of $\mathrm{MA}(1)$ process at lag $1-0.5<\rho_{1}^{\mathrm{MA}(1)}<0.5$. This implies that $-0.5<\frac{-\theta_{1}}{1+\theta_{1}^{2}}<0.5$. Hence, for Non-duality, it is expected that $-0.5<\phi_{1}<0.5$, since $\phi_{1}=\frac{-\theta_{1}}{1+\theta_{1}^{2}}$.

In solving Equation (2.4), two cases arise.

Case I: Non-Duality Region in movement from stationary AR(1) process to invertible $\mathrm{MA}(1)$ process.

The solutions for $\theta_{1}$ in the resulting quadratic Equation (2.8) are

$$
\theta_{1}=\frac{-1 \pm \sqrt{1-4 \phi_{1}^{2}}}{2 \phi_{1}}
$$

For real values $D=1-4 \phi_{1}^{2} \geq 0, \Rightarrow 4 \phi_{1}^{2} \geq 1, \phi_{1}^{2} \geq \frac{1}{4}$ and $-\frac{1}{2}<\phi_{1}<\frac{1}{2}$.

For $-1<\theta_{1}<1$, the acceptable value of $\theta_{1}$ is

$$
\theta_{1}=\frac{-1+\sqrt{1-4 \phi_{1}^{2}}}{2 \phi_{1}}
$$

Therefore when moving from stationary $\mathrm{AR}(1)$ process to invertible $\mathrm{MA}(1)$ process, the region of breakdown of duality is determined using (2.1), and illustrated in Table 1.

\begin{tabular}{|c|c|c|c|}
\hline \multirow{3}{*}{$\begin{array}{l}\text { Degree of approximation } \\
\text { allowable for } h_{k}\end{array}$} & \multicolumn{2}{|c|}{ Region of Non-duality } & \multirow{3}{*}{ Remark } \\
\hline & AR(1) Process & MA(1) Process & \\
\hline & $\phi_{1}$ & $\theta_{1}$ & \\
\hline 1 & {$[-0.38,0.38]$} & {$[-0.46,0.46]$} & $\begin{array}{l}\text { Negative values } \phi_{1} \text { are mapped into positive } \\
\text { values of } \theta_{1} \text { and vice versa }\end{array}$ \\
\hline 2 & {$[-0.24,0.24]$} & {$[-0.26,0.26]$} & $\begin{array}{l}\text { Negative values } \phi_{1} \text { are mapped into positive } \\
\text { values of } \theta_{1} \text { and vice versa }\end{array}$ \\
\hline 3 & {$[-0.14,0.14]$} & {$[-0.14,0.14]$} & $\begin{array}{l}\text { Negative values } \phi_{1} \text { are mapped into positive } \\
\text { values of } \theta_{1} \text { and vice versa }\end{array}$ \\
\hline 4 & {$[-0.08,0.08]$} & {$[-0.08,0.08]$} & $\begin{array}{l}\text { Negative values } \phi_{1} \text { are mapped into positive } \\
\text { values of } \theta_{1} \text { and vice versa }\end{array}$ \\
\hline
\end{tabular}

Case II: Non-Duality Region in movement from invertible MA(1) process to stationary $\mathrm{AR}(1)$ process.

Table 1. Regions of $\phi_{1}$ and $\theta_{1}$ for non-duality of AR(1) and MA(1) processes. 
When it is assumed that the process is invertible $\mathrm{MA}(1)$, that is $\theta_{1}$ is known, and it is required to determine the region of Non-Duality, $\phi_{1}$ is determined in terms of $\theta_{1}$ subject to $-1<\phi_{1}<1$ using Equation (2.8). Hence, when moving from invertible $\mathrm{MA}(1)$ process to stationary $\mathrm{AR}(1)$ process, the region of breakdown of duality is determined using (2.1), and illustrated in Table 2.

Remark 2.1: As shown in Table 1 and Table 2, if we allow beyond two or more decimal places, the intervals of breakdown of duality are the same for AR(1) process and MA(1) process. However, beyond three or more decimal places, the intervals are quite small and whose significance may be questionable. Therefore, we recommend that for breakdown of duality, one to three decimal places of the absolute difference between the lag $k$ corresponding autocovariances of stationary $\operatorname{AR}(p)$ process and that for the invertible $\mathrm{MA}(p)$ process may be allowed.

\subsection{Non-Duality between AR(2) and MA(2) Processes}

For the model and autocovariances of stationary autoregressive process of order two $(\operatorname{AR}(2))[20]$ :

$$
\begin{aligned}
\tilde{X}_{t}=\phi_{1} \tilde{X}_{t-1}+\phi_{2} \tilde{X}_{t-2}+e_{t} ; e_{t} \sim N\left(0, \sigma^{2}\right), \phi_{2}-\phi_{1}<1, \phi_{2}+\phi_{1}<1,-1<\phi_{2}<1 \\
R^{\operatorname{AR}(2)}(k)=\left\{\begin{array}{l}
\frac{\left(1-\phi_{2}\right) \sigma^{2}}{\left(1+\phi_{2}\right)\left(1-\phi_{2}+\phi_{1}\right)\left(1-\phi_{2}-\phi_{1}\right)}, k=0 \\
\frac{\phi_{1} \sigma^{2}}{\left(1+\phi_{2}\right)\left(1-\phi_{2}+\phi_{1}\right)\left(1-\phi_{2}-\phi_{1}\right)} ; k=1 \\
\frac{\left(\phi_{1}^{2}+\phi_{2}\left(1-\phi_{2}\right)\right) \sigma^{2}}{\left(1+\phi_{2}\right)\left(1-\phi_{2}+\phi_{1}\right)\left(1-\phi_{2}-\phi_{1}\right)} ; k=2 \\
\phi_{1} R(k-1)+\phi_{2} R(k-2), \quad k>2
\end{array}\right.
\end{aligned}
$$

and for invertible moving average process of order one (MA(1)) [20]:

\begin{tabular}{|c|c|c|c|}
\hline \multirow{3}{*}{$\begin{array}{l}\text { Degree of approximation } \\
\text { allowable for } h_{k}\end{array}$} & \multicolumn{2}{|c|}{ Region of Non-duality } & \multirow{3}{*}{ Remark } \\
\hline & MA(1) Process & AR(1) Process & \\
\hline & $\theta_{1}$ & $\phi_{1}$ & \\
\hline 1 & {$[-0.47,0.47]$} & {$[-0.38,0.38]$} & $\begin{array}{l}\text { Negative values } \theta_{1} \text { are mapped into positive } \\
\text { values of } \phi_{1} \text { and vice versa }\end{array}$ \\
\hline 2 & {$[-0.26,0.26]$} & {$[-0.24,0.24]$} & $\begin{array}{l}\text { Negative values } \theta_{1} \text { are mapped into positive } \\
\text { values of } \phi_{1} \text { and vice versa }\end{array}$ \\
\hline 3 & {$[-0.14,0.14]$} & {$[-0.14,0.14]$} & $\begin{array}{l}\text { Negative values } \theta_{1} \text { are mapped into positive } \\
\text { values of } \phi_{1} \text { and vice versa }\end{array}$ \\
\hline 4 & {$[-0.08,0.08]$} & {$[-0.08,0.08]$} & $\begin{array}{l}\text { Negative values } \theta_{1} \text { are mapped into positive } \\
\text { values of } \phi_{1} \text { and vice versa }\end{array}$ \\
\hline
\end{tabular}

Table 2. Regions of $\theta_{1}$ and $\phi_{1}$ for non-duality of MA(1) and AR(1) Processes. 


$$
\begin{gathered}
\tilde{X}_{t}=e_{t}-\theta_{1} e_{t-1}-\theta_{2} e_{t-2} ; e_{t} \sim N\left(0, \sigma^{2}\right), \theta_{2}-\theta_{1}<1, \theta_{2}+\theta_{1}<1,-1<\theta_{2}<1 \\
R^{\mathrm{MA}(2)}(k)=\left\{\begin{array}{l}
\sigma^{2}\left(1+\theta_{1}^{2}+\theta_{2}^{2}\right), k=0 \\
-\theta_{1}\left(1-\theta_{2}\right) \sigma^{2}, k=1 \\
-\theta_{2} \sigma^{2}, k=2 \\
0, k>2
\end{array}\right.
\end{gathered}
$$

By equating corresponding non-zero autocovariances from stationary $\mathrm{AR}(2)$ process and invertible MA(2) process respectively, we obtain

$$
\begin{gathered}
\frac{1-\phi_{2}}{\left(1+\phi_{2}\right)\left(1-\phi_{2}+\phi_{1}\right)\left(1-\phi_{2}-\phi_{1}\right)}=1+\theta_{1}^{2}+\theta_{2}^{2} \\
\frac{\phi_{1}}{\left(1+\phi_{2}\right)\left(1-\phi_{2}+\phi_{1}\right)\left(1-\phi_{2}-\phi_{1}\right)}=-\theta_{1}\left(1-\theta_{2}\right) \\
\frac{\phi_{1}^{2}+\phi_{2}\left(1-\phi_{2}\right)}{\left(1+\phi_{2}\right)\left(1-\phi_{2}+\phi_{1}\right)\left(1-\phi_{2}-\phi_{1}\right)}=-\theta_{2}
\end{gathered}
$$

From (2.15), we have

$$
\frac{1}{\left(1+\phi_{2}\right)\left(1-\phi_{2}+\phi_{1}\right)\left(1-\phi_{2}-\phi_{1}\right)}=\frac{1+\theta_{1}^{2}+\theta_{2}^{2}}{1-\phi_{2}}
$$

From (2.16), we have

$$
\frac{1}{\left(1+\phi_{2}\right)\left(1-\phi_{2}+\phi_{1}\right)\left(1-\phi_{2}-\phi_{1}\right)}=\frac{-\theta_{1}\left(1-\theta_{2}\right)}{\phi_{1}}
$$

From (2.17)

$$
\frac{1}{\left(1+\phi_{2}\right)\left(1-\phi_{2}+\phi_{1}\right)\left(1-\phi_{2}-\phi_{1}\right)}=\frac{-\theta_{2}}{\phi_{1}^{2}+\phi_{2}\left(1-\phi_{2}\right)}
$$

Equating the right hand sides of (2.18), (2.19) and (2.20), we obtain

$$
\frac{-\theta_{1}\left(1-\theta_{2}\right)}{\phi_{1}}=\frac{-\theta_{2}}{\phi_{1}^{2}+\phi_{2}\left(1-\phi_{2}\right)}=\frac{1}{\left(1+\phi_{2}\right)\left(1-\phi_{2}+\phi_{1}\right)\left(1-\phi_{2}-\phi_{1}\right)}
$$

Hence, Equation (2.21) is the relational equation connecting $\phi_{1}, \phi_{2}, \theta_{1}$ and $\theta_{2}$. Using transitivity rule, these three equations can be used to obtain the desired solutions. That is

$$
\begin{gathered}
\frac{-\theta_{1}\left(1-\theta_{2}\right)}{\phi_{1}}=\frac{-\theta_{2}}{\phi_{1}^{2}+\phi_{2}\left(1-\phi_{2}\right)} \\
\frac{-\theta_{1}\left(1-\theta_{2}\right)}{\phi_{1}}=\frac{1}{\left(1+\phi_{2}\right)\left(1-\phi_{2}+\phi_{1}\right)\left(1-\phi_{2}-\phi_{1}\right)} \\
\frac{-\theta_{2}}{\phi_{1}^{2}+\phi_{2}\left(1-\phi_{2}\right)}=\frac{1}{\left(1+\phi_{2}\right)\left(1-\phi_{2}+\phi_{1}\right)\left(1-\phi_{2}-\phi_{1}\right)}
\end{gathered}
$$

In considering the above three equations, two cases arise resulting in the 
Non-Duality region.

Case I: Non-Duality Region in movement from stationary $\operatorname{AR}(2)$ process to invertible $\mathrm{MA}(2)$ process.

Given the stationary $\operatorname{AR}(2)$ process, we determine $\theta_{1}$ and $\theta_{2}$ (in terms $\phi_{1}$ and $\phi_{2}$ ) that must satisfy the invertibility conditions explicitly from the relational Equation (2.24) as

$$
\theta_{2}=\frac{-\left(\phi_{1}^{2}+\phi_{2}\left(1-\phi_{2}\right)\right)}{\left(1+\phi_{2}\right)\left(1-\phi_{2}+\phi_{1}\right)\left(1-\phi_{2}-\phi_{1}\right)}=\frac{-\phi_{1}^{2}-\phi_{2}\left(1-\phi_{2}\right)}{\left(1+\phi_{2}\right)\left(1-\phi_{2}+\phi_{1}\right)\left(1-\phi_{2}-\phi_{1}\right)}
$$

Substituting (2.25) into (2.23), we obtain $\theta_{1}$ as

$$
\theta_{1}=\frac{-\phi_{1}}{\left(\left(1+\phi_{2}\right)\left(1-\phi_{2}+\phi_{1}\right)\left(1-\phi_{2}-\phi_{1}\right)\right)+\left(\phi_{1}^{2}+\phi_{2}\left(1-\phi_{2}\right)\right)}
$$

From the invertibility conditions of MA(2) process, $\left|\theta_{2}\right|<1$ implies that

$$
\left|\theta_{2}\right|=\left|\frac{-\left(\phi_{1}^{2}+\phi_{2}\left(1-\phi_{2}\right)\right)}{\left(1+\phi_{2}\right)\left(1-\phi_{2}+\phi_{1}\right)\left(1-\phi_{2}-\phi_{1}\right)}\right|<1
$$

The expression (2.27) is added to the stationarity conditions to obtain the Non-duality region/conditions for movement from $\operatorname{AR}(2)$ to $M A(2)$ processes as

$$
\left.\begin{array}{l}
\left.\begin{array}{l}
\phi_{2}-\phi_{1}<1 \\
\phi_{2}+\phi_{1}<1 \\
-1<\phi_{2}<1
\end{array}\right\} \text { stationarity conditions } \\
\mid \begin{array}{r}
-\left(\phi_{1}^{2}+\phi_{2}\left(1-\phi_{2}\right)\right) \\
\left(1+\phi_{2}\right)\left(1-\phi_{2}+\phi_{1}\right)\left(1-\phi_{2}-\phi_{1}\right)
\end{array}
\end{array}\right\} \text { Non-duality region }
$$

This region (2.28) is illustrated graphically in Figure 1. Then, using (2.1), the re-

\begin{tabular}{|c|c|c|c|c|c|}
\hline \multirow{3}{*}{$\begin{array}{c}\text { Degree of } \\
\text { approximation } \\
\text { allowable for } h_{k}\end{array}$} & \multicolumn{4}{|c|}{ Region of Non-duality } & \multirow{3}{*}{ Remark } \\
\hline & \multicolumn{2}{|c|}{ AR(2) Process } & \multicolumn{2}{|c|}{ MA(2) Process } & \\
\hline & $\phi_{1}$ & $\phi_{2}$ & $\theta_{1}$ & $\theta_{2}$ & \\
\hline 1 & {$[-0.30,0.30]$} & {$[-0.30,0.30]$} & {$[-0.37,0.37]$} & {$[-0.43,0.32]$} & $\begin{array}{l}\text { positive values }\left(\phi_{1}, \phi_{2}\right) \text { are mapped into } \\
\text { negative values of }\left(\theta_{1}, \theta_{2}\right) \text { and vice versa }\end{array}$ \\
\hline 2 & {$[-0.30,0.30]$} & {$[-0.20,0.20]$} & {$[-0.30,0.30]$} & {$[-0.22,0.20]$} & $\begin{array}{l}\text { positive values }\left(\phi_{1}, \phi_{2}\right) \text { are mapped into } \\
\text { negative values of }\left(\theta_{1}, \theta_{2}\right) \text { and vice versa }\end{array}$ \\
\hline 3 & {$[-0.10,0.10]$} & -0.10 & {$[-0.10,0.10]$} & 0.09 & $\begin{array}{l}\text { positive values }\left(\phi_{1}, \phi_{2}\right) \text { are mapped into } \\
\text { negative values of }\left(\theta_{1}, \theta_{2}\right) \text { and vice versa }\end{array}$ \\
\hline
\end{tabular}
gion of breakdown of duality when moving from stationary $\mathrm{AR}(2)$ process to invertible MA(2) process is determined. This region determined is shown in Table 3.

Table 3. Regions of $\left(\phi_{1}, \phi_{2}\right)$ and $\left(\theta_{1}, \theta_{2}\right)$ for non-duality of $\operatorname{AR}(2)$ and $\mathrm{MA}(2)$ processes. 


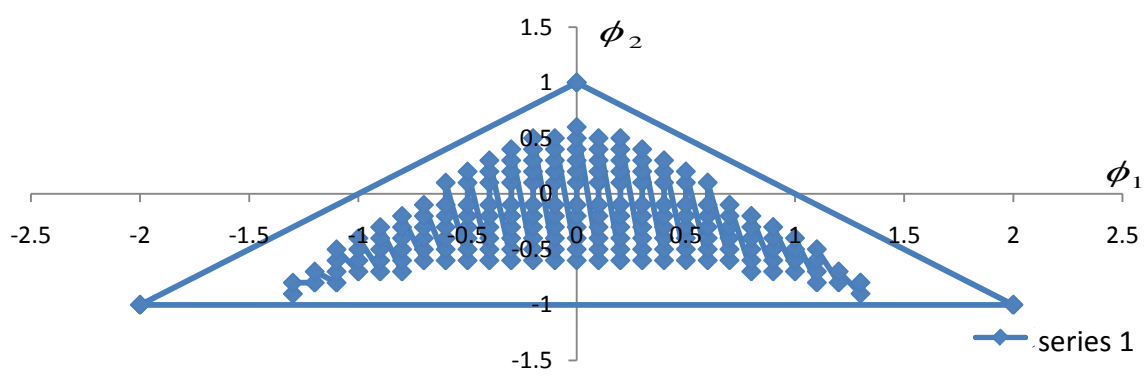

Figure 1. The shaded portion under the triangular region (stationarity region) specifies the non-duality region for movement from AR(2) Process to MA(2) process.

Case II: Non-Duality region in movement from invertible MA(2) process to stationary $\mathrm{AR}(2)$ process.

Given the invertible MA(2) process, we determine the values of ( $\phi_{1}$ and $\left.\phi_{2}\right)$ that lead to break down in duality from Equation (2.22). Solving for $\phi_{1}$ and $\phi_{2}$, the expression reduces to the quadratic Equation

$$
\phi_{1}^{2}-\left[\frac{\theta_{2}}{\theta_{1}\left(1-\theta_{2}\right)}\right] \phi_{1}+\phi_{2}\left(1-\phi_{2}\right)=0
$$

Equation (2.29) is a quadratic equation in both $\phi_{1}$ and $\phi_{2}$. By either solving for $\phi_{1}$ first in (2.29) or $\phi_{2}$ first in (2.29), Case II breaks into two-sub cases. Case II (a) involves solving for $\phi_{1}$ first in (2.29) and we obtain

$$
\phi_{1}=\frac{\frac{\theta_{2}}{\theta_{1}\left(1-\theta_{2}\right)} \pm \sqrt{\left[\frac{\theta_{2}}{\theta_{1}\left(1-\theta_{2}\right)}\right]^{2}-4 \phi_{2}\left(1-\phi_{2}\right)}}{2}
$$

for fixed $\theta_{1}$ and $\theta_{2}$ with $-1<\phi_{2}<1$. For real roots of $\phi_{1}$, it is requested that the discriminant

$$
D=4 \phi_{2}^{2}-4 \phi_{2}+\left[\frac{\theta_{2}}{\theta_{1}\left(1-\theta_{2}\right)}\right]^{2} \geq 0
$$

For fixed values of $\theta_{1}$ and $\theta_{2}$ satisfying the invertibility conditions, Equation (2.31) is a quadratic inequality in $\phi_{2}$. First, we solve for $\phi_{2}$ in

$$
4 \phi_{2}^{2}-4 \phi_{2}+\left[\frac{\theta_{2}}{\theta_{1}\left(1-\theta_{2}\right)}\right]^{2}=0
$$

to obtain

$$
\phi_{2}=\frac{1 \pm \sqrt{1-\left[\frac{\theta_{2}}{\theta_{1}\left(1-\theta_{2}\right)}\right]^{2}}}{2}
$$

Since (2.26) is a quadratic inequality, the roots of (2.33) split the interval for $\phi_{2}$, $\phi_{2} \in(-1,1)$, into three intervals [29] [30]. If we define

$$
W=\frac{\theta_{2}}{\theta_{1}\left(1-\theta_{2}\right)} .
$$


then, the intervals are $\left(-1, \frac{1-\sqrt{1-W^{2}}}{2}\right),\left[\frac{1-\sqrt{1-W^{2}}}{2}, \frac{1+\sqrt{1-W^{2}}}{2}\right]$ and $\left(\frac{1+\sqrt{1-W^{2}}}{2}, 1\right)$.

From (2.33), it is clear that for two distinct real roots of $\phi_{2}$;

$$
\begin{aligned}
& {\left[\frac{\theta_{2}}{\theta_{1}\left(1-\theta_{2}\right)}\right]^{2}<1} \\
& \Rightarrow\left|\frac{\theta_{2}}{\theta_{1}\left(1-\theta_{2}\right)}\right|<1
\end{aligned}
$$

Similarly, Case II (b) involves solving for $\phi_{2}$ first in (2.29) to obtain

$$
\phi_{2}=\frac{1 \pm \sqrt{1+4 \phi_{1}\left[\phi_{1}-\left[\frac{\theta_{2}}{\theta_{1}\left(1-\theta_{2}\right)}\right]\right]}}{2}
$$

for fixed $\theta_{1}$ and $\theta_{2}$ with $-2<\phi_{1}<2$. For real roots of $\phi_{2}$,

$$
1+4 \phi_{1}\left[\phi_{1}-\left[\frac{\theta_{2}}{\theta_{1}\left(1-\theta_{2}\right)}\right]\right] \geq 0
$$

Equation (2.38) is a quadratic inequality on $\phi_{1}$. Solving for $\phi_{1}$, we use

$$
1+4 \phi_{1}\left[\phi_{1}-\left[\frac{\theta_{2}}{\theta_{1}\left(1-\theta_{2}\right)}\right]\right]=0
$$

to obtain

$$
\phi_{1}=\frac{\frac{\theta_{2}}{\theta_{1}\left(1-\theta_{2}\right)} \pm \sqrt{\left[\frac{\theta_{2}}{\theta_{1}\left(1-\theta_{2}\right)}\right]^{2}-1}}{2}
$$

for fixed $\theta_{1}$ and $\theta_{2}$. Since (2.38) is a quadratic inequality, (2.40) split the interval for $\phi_{1}, \phi_{1} \in(-2,2)$, into three intervals [30]. The intervals are: $\left(-2, \frac{W-\sqrt{W^{2}-1}}{2}\right),\left[\frac{W-\sqrt{W^{2}-1}}{2}, \frac{W+\sqrt{W^{2}-1}}{2}\right]$ and $\left(\frac{W+\sqrt{W^{2}-1}}{2}, 2\right)$

From (2.40), it is clear that for distinct real roots of $\phi_{1}$;

$$
\begin{aligned}
& {\left[\frac{\theta_{2}}{\theta_{1}\left(1-\theta_{2}\right)}\right]^{2}>1} \\
& \Rightarrow\left|\frac{\theta_{2}}{\theta_{1}\left(1-\theta_{2}\right)}\right|>1
\end{aligned}
$$

Equation (2.36) and (2.42) combined with the invertibility conditions gives what we call the Non-Duality conditions/region when going from $\operatorname{MA}(2)$ to $\operatorname{AR}(2)$ processes. The Non-Duality conditions/region when moving from $\mathrm{MA}(2)$ to $\operatorname{AR}(2)$ processes is given as 


$$
\left.\begin{array}{l}
\left.\begin{array}{l}
\theta_{2}-\theta_{1}<1 \\
\theta_{2}+\theta_{1}<1 \\
-1<\theta_{2}<1
\end{array}\right\} \text { invertibility conditions } \\
\left|\frac{\theta_{2}}{\theta_{1}\left(1-\theta_{2}\right)}\right| \neq 1
\end{array}\right\} \text { Non-duality region }
$$

See Figure 2 for illustration of Equation (2.43). Then, using (2.1), the region of breakdown of duality when moving from invertible MA(2) process to stationary $\mathrm{AR}(2)$ process for case IIa and case IIb are determined and illustrated in Table 4 and Table 5 respectively.

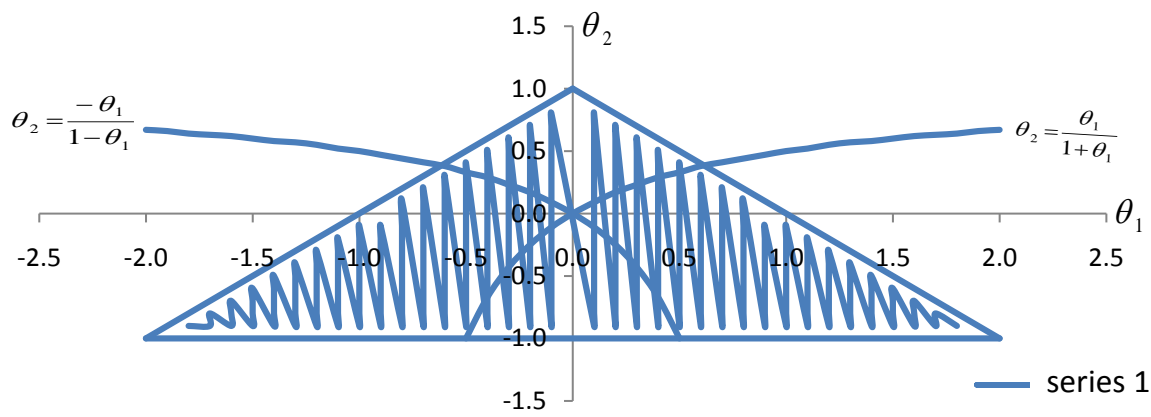

Figure 2. The shaded portion under the triangular region (invertibility region) specifies the non-duality region for movement from MA(2) Process to $\operatorname{AR}(2)$ process.

Table 4. Regions of $\left(\theta_{1}, \theta_{2}\right)$ and $\left(\phi_{1}, \phi_{2}\right)$ for non-duality of MA(2) and $\mathrm{AR}(2)$ processes.

\begin{tabular}{|c|c|c|c|c|c|}
\hline \multirow{3}{*}{$\begin{array}{c}\text { Degree of } \\
\text { approximation } \\
\text { allowable for } h_{k}\end{array}$} & \multicolumn{4}{|c|}{ Region of Non-duality } & \multirow{3}{*}{ Remark } \\
\hline & \multicolumn{2}{|c|}{ MA(2) Process } & \multicolumn{2}{|c|}{$\mathrm{AR}(2)$ Process } & \\
\hline & $\theta_{1}$ & $\theta_{2}$ & $\phi_{1}$ & $\phi_{2}$ & \\
\hline 1 & 0.10 & -0.11 & {$[-0.12,-0.07]$} & {$[0.07,0.12]$} & $\begin{array}{l}\text { positive values }\left(\theta_{1}, \theta_{2}\right) \text { are mapped into } \\
\text { negative values of }\left(\phi_{1}, \phi_{2}\right) \text { and vice versa }\end{array}$ \\
\hline 2 & 0.10 & -0.11 & -0.10 & 0.10 & $\begin{array}{l}\text { positive values }\left(\theta_{1}, \theta_{2}\right) \text { are mapped into } \\
\text { negative values of }\left(\phi_{1}, \phi_{2}\right) \text { and vice versa }\end{array}$ \\
\hline
\end{tabular}

Table 5. Regions of $\left(\theta_{1}, \theta_{2}\right)$ and $\left(\phi_{1}, \phi_{2}\right)$ for non-duality of MA(2) and $\mathrm{AR}(2)$ processes.

\begin{tabular}{|c|c|c|c|c|c|}
\hline \multirow{3}{*}{$\begin{array}{c}\text { Degree of } \\
\text { approximation } \\
\text { allowable for } h_{k}\end{array}$} & \multicolumn{4}{|c|}{ Region of Non-duality } & \multirow{3}{*}{ Remark } \\
\hline & \multicolumn{2}{|c|}{ MA(2) Process } & \multicolumn{2}{|c|}{ AR(2) Process } & \\
\hline & $\theta_{1}$ & $\theta_{2}$ & $\phi_{1}$ & $\phi_{2}$ & \\
\hline 1 & -0.11 & -0.22 & {$[0.09,0.11]$} & {$[0.17,0.21]$} & $\begin{array}{l}\text { positive values }\left(\theta_{1}, \theta_{2}\right) \text { are mapped into } \\
\text { negative values of }\left(\phi_{1}, \phi_{2}\right) \text { and vice versa }\end{array}$ \\
\hline 2 & -0.11 & -0.22 & 0.10 & 0.20 & $\begin{array}{l}\text { positive values }\left(\theta_{1}, \theta_{2}\right) \text { are mapped into } \\
\text { negative values of }\left(\phi_{1}, \phi_{2}\right) \text { and vice versa }\end{array}$ \\
\hline
\end{tabular}




\section{Empirical Examples}

This section presents some empirical examples to illustrate the results obtained in Section 2. Both simulated and real life time series data were used for the illustration. The first set of simulations consist of one thousand (1000) stationary $\mathrm{AR}(2)$ series of 120 observations each, simulated using $e_{t} \sim N\left(0, \sigma^{2}\right)$ and $\left(\varphi_{1}, \varphi_{2}\right)=(-0.30,-0.30)$ which satisfy the non-duality conditions defined in Equation (2.28). The estimates of the autocorrelation function, acf $\left(\rho_{k}\right)$ and the partial autocorrelation function, pacf $\left(\phi_{k k}\right)$ of the simulated series cut off after lag two. These indicate that the patterns in the series may be adequately described by either the stationary $\operatorname{AR}(2)$ process or the invertible $\mathrm{MA}(2)$ process. Since the series were simulated from stationary AR(2) process, an MA(2) model was fitted to the series. The estimate of the acf and the pacf of the residuals from the fitted MA(2) model all lie within 2 standard deviations from mean (zero) indicating that the fitted model is adequate. The estimates of the means and variances of the residuals are also not significantly different from 0 and 1 respectively. These indicate that the model adequately describes the pattern in the simulated series. The estimates of $\theta_{1}$ and $\theta_{2}$, obtained using MINITAB 17 series software are shown in Table 6 (for ten simulated series only for want of space). As Table 6 shows, the estimates also: (i) satisfy the invertibility conditions and (ii) compare favourably well, in absolute terms, with those of stationary $A R(2)$ process but with opposite signs. These indicate that a stationary $\mathrm{AR}(2)$ process can be adequately represented by an invertible MA(2) process contrary to the widely held duality concept.

The second set of simulations consists of one thousand (1000) invertible MA(2) series of 120 observations each, simulated using $e_{t} \sim N\left(0, \sigma^{2}\right)$ and $\left(\theta_{1}, \theta_{2}\right)=(0.37,0.27)$ which satisfy the non-duality conditions defined in Equation (2.43). The estimates of the autocorrelation function, acf $\left(\rho_{k}\right)$ and the partial autocorrelation function, pacf $\left(\phi_{k k}\right)$ of the simulated series cut off after lag two. These indicate that the patterns in the series may be adequately described by either the invertible MA(2) process or the stationary AR(2) process. Since the series were simulated from invertible MA(2) process, the AR(2) model was fitted to the series. The estimates of the mean, variance, acf and the pacf of the residuals from the fitted $\operatorname{AR}(2)$ model indicate that the model adequately describes the pattern in the simulated series. The estimates of $\phi_{1}$ and $\phi_{2}$ obtained using MINITAB 17 series software shown in Table 7 (for ten simulations for want of space) also: (i) satisfy the stationarity conditions and (ii) compare favourably well, in absolute terms, with those of invertible MA(2) process with opposite signs. These indicate that an invertible $\mathrm{MA}(2)$ process can be adequately represented by a stationary $\mathrm{AR}(2)$ process contrary to the widely held duality concept.

Furthermore, the breakdown of duality was illustrated using the real life data on the monthly average exchange rate of Naira per unit of CFA currency collected from Central Bank of Nigeria for the period January 2002 to December 2013 [31] [32]. The estimates of $\rho_{k}$ and $\phi_{k k}$ of the original series $\left(X_{t}\right)$ shown 
Table 6. Estimates of parameters of MA(2) model fitted to simulated AR(2) process with $\phi_{1}=-0.30, \phi_{2}=-0.30$ and $e_{t} \sim N(0,1)$.

\begin{tabular}{|c|c|c|c|c|c|c|c|c|c|c|}
\hline \multirow{2}{*}{ S/No. } & \multirow{2}{*}{$i$} & \multicolumn{4}{|c|}{ AR(2) Model } & \multirow{2}{*}{$i$} & \multicolumn{4}{|c|}{ MA(2) Model } \\
\hline & & $\hat{\phi}_{i}$ & $\operatorname{std}\left(\hat{\phi}_{i}\right)$ & t-value & $\hat{\sigma}^{2}$ & & $\hat{\theta}_{i}$ & $\operatorname{std}\left(\hat{\theta}_{i}\right)$ & t-value & $\hat{\sigma}^{2}$ \\
\hline \multirow[b]{2}{*}{1} & 1 & -0.3241 & 0.0943 & -3.44 & \multirow{2}{*}{1.1220} & 1 & 0.3105 & 0.0954 & 3.25 & \multirow{2}{*}{1.1020} \\
\hline & 2 & -0.3612 & 0.0953 & -3.79 & & 2 & 0.3286 & 0.0958 & 3.43 & \\
\hline \multirow[b]{2}{*}{2} & 1 & -0.2162 & 0.0961 & -2.25 & \multirow{2}{*}{1.0890} & 1 & 0.2218 & 0.0974 & 2.28 & \multirow[b]{2}{*}{1.0900} \\
\hline & 2 & -0.3130 & 0.0964 & -3.25 & & 2 & 0.2563 & 0.0975 & 2.63 & \\
\hline \multirow{2}{*}{3} & 1 & -0.2127 & 0.0974 & -2.18 & \multirow{2}{*}{0.8725} & 1 & 0.2718 & 0.0975 & 2.79 & \multirow{2}{*}{0.8520} \\
\hline & 2 & -0.3010 & 0.0973 & -3.09 & & 2 & 0.2762 & 0.0975 & 2.83 & \\
\hline \multirow[b]{2}{*}{4} & 1 & -0.3098 & 0.0944 & -3.28 & \multirow{2}{*}{0.9103} & 1 & 0.3323 & 0.0979 & 3.39 & \multirow{2}{*}{0.9220} \\
\hline & 2 & -0.3606 & 0.0945 & -3.82 & & 2 & 0.2468 & 0.0981 & 2.52 & \\
\hline \multirow{2}{*}{5} & 1 & -0.2619 & 0.0934 & -2.81 & \multirow{2}{*}{1.1780} & 1 & 0.2009 & 0.0960 & 2.09 & \multirow{2}{*}{1.2210} \\
\hline & 2 & -0.3873 & 0.0934 & -4.15 & & 2 & 0.3390 & 0.0963 & 3.52 & \\
\hline \multirow{2}{*}{6} & 1 & -0.2957 & 0.0909 & -3.25 & \multirow{2}{*}{0.8452} & 1 & 0.2356 & 0.0946 & 2.49 & \multirow{2}{*}{0.8851} \\
\hline & 2 & -0.4419 & 0.0916 & -4.82 & & 2 & 0.3531 & 0.0953 & 3.71 & \\
\hline \multirow{2}{*}{7} & 1 & -0.2177 & 0.0961 & -2.26 & \multirow{2}{*}{1.0073} & 1 & 0.2896 & 0.0961 & 3.02 & \multirow{2}{*}{0.9750} \\
\hline & 2 & -0.3064 & 0.0962 & -3.18 & & 2 & 0.3080 & 0.0961 & 3.21 & \\
\hline \multirow{2}{*}{8} & 1 & -0.2970 & 0.0949 & -3.13 & \multirow{2}{*}{0.9185} & 1 & 0.3579 & 0.0972 & 3.68 & \multirow{2}{*}{0.9009} \\
\hline & 2 & -0.3395 & 0.0951 & -3.57 & & 2 & 0.2726 & 0.0972 & 2.80 & \\
\hline \multirow{2}{*}{9} & 1 & -0.2634 & 0.0953 & -2.76 & \multirow{2}{*}{1.092} & 1 & 0.2035 & 0.0983 & 2.07 & \multirow{2}{*}{1.1390} \\
\hline & 2 & -0.3477 & 0.0956 & -3.64 & & 2 & 0.2255 & 0.0983 & 2.29 & \\
\hline \multirow{2}{*}{10} & 1 & -0.3409 & 0.0947 & -3.60 & & 1 & 0.3399 & 0.0992 & 3.43 & \\
\hline & 2 & -0.3476 & 0.0949 & -3.66 & & 2 & 0.2084 & 0.1017 & 2.05 & \\
\hline
\end{tabular}

Table 7. Estimates of parameters of AR(2) model fitted to simulated MA(2) model with $\theta_{1}=0.37, \theta_{2}=0.27$ and $e_{t} \sim N(0,1)$.

\begin{tabular}{|c|c|c|c|c|c|c|c|c|c|c|}
\hline \multirow{2}{*}{ S/No. } & \multirow{2}{*}{$i$} & \multicolumn{4}{|c|}{ MA(2) Model } & \multirow{2}{*}{$i$} & \multicolumn{4}{|c|}{ AR(2) Model } \\
\hline & & $\hat{\theta}_{i}$ & $\operatorname{std}\left(\hat{\theta}_{i}\right)$ & t-value & $\hat{\sigma}^{2}$ & & $\hat{\phi}_{i}$ & $\operatorname{std}\left(\hat{\phi}_{i}\right)$ & $\mathrm{t}$-value & $\hat{\sigma}^{2}$ \\
\hline \multirow{2}{*}{1} & 1 & 0.3427 & 0.0981 & 3.49 & \multirow{2}{*}{1.0136} & 1 & -0.2615 & 0.0967 & -2.70 & \multirow{2}{*}{1.0450} \\
\hline & 2 & 0.2862 & 0.0984 & 2.91 & & 2 & -0.3528 & 0.0971 & -3.63 & \\
\hline \multirow{2}{*}{2} & 1 & 0.3513 & 0.0943 & 3.72 & \multirow{2}{*}{1.0510} & 1 & -0.2013 & 0.0964 & -2.09 & \multirow{2}{*}{1.1560} \\
\hline & 2 & 0.3412 & 0.0943 & 3.62 & & 2 & -0.3011 & 0.0966 & -3.12 & \\
\hline \multirow{2}{*}{3} & 1 & 0.3902 & 0.0929 & 4.20 & \multirow{2}{*}{1.1770} & 1 & -0.3004 & 0.0953 & -3.15 & \multirow{2}{*}{1.2770} \\
\hline & 2 & 0.3940 & 0.0933 & 4.23 & & 2 & -0.3500 & 0.0953 & -3.67 & \\
\hline \multirow{2}{*}{4} & 1 & 0.3629 & 0.0967 & 3.75 & \multirow{2}{*}{1.0590} & 1 & -0.2879 & 0.0973 & -2.96 & \multirow{2}{*}{1.1230} \\
\hline & 2 & 0.2958 & 0.0970 & 3.05 & & 2 & -0.2709 & 0.0973 & -2.78 & \\
\hline
\end{tabular}




\begin{tabular}{|c|c|c|c|c|c|c|c|c|c|c|}
\hline \multicolumn{11}{|c|}{ Continued } \\
\hline \multirow{2}{*}{5} & 1 & 0.3322 & 0.0977 & 3.40 & \multirow{2}{*}{0.9375} & 1 & -0.2472 & 0.0970 & -2.55 & \multirow{2}{*}{0.9769} \\
\hline & 2 & 0.2830 & 0.0977 & 2.90 & & 2 & -0.2901 & 0.0994 & -2.92 & \\
\hline \multirow{2}{*}{6} & 1 & 0.4133 & 0.0975 & & \multirow{2}{*}{0.9956} & 1 & -0.3220 & 0.0963 & -3.34 & \multirow{2}{*}{1.0670} \\
\hline & 2 & 0.2674 & 0.0991 & 2.70 & & 2 & -0.3053 & 0.0962 & -3.17 & \\
\hline \multirow{2}{*}{7} & 1 & 0.2955 & 0.0983 & 3.01 & \multirow{2}{*}{0.9634} & 1 & -0.2575 & 0.0967 & -2.66 & \multirow{2}{*}{0.9719} \\
\hline & 2 & 0.2476 & 0.0990 & 2.50 & & 2 & -0.2996 & 0.0983 & -3.05 & \\
\hline \multirow{2}{*}{8} & 1 & 0.3655 & 0.0987 & 3.70 & \multirow{2}{*}{1.0770} & 1 & -0.3685 & 0.0933 & -3.95 & \multirow{2}{*}{1.0540} \\
\hline & 2 & 0.2279 & 0.0987 & 2.31 & & 2 & -0.3906 & 0.0941 & -4.15 & \\
\hline \multirow{2}{*}{9} & 1 & 0.3554 & 0.0976 & 3.64 & \multirow{2}{*}{1.2330} & 1 & -0.3564 & 0.0954 & -4.74 & \multirow{2}{*}{1.2280} \\
\hline & 2 & 0.2808 & 0.0978 & 2.87 & & 2 & -0.3401 & 0.0961 & -3.54 & \\
\hline \multirow{2}{*}{10} & 1 & 0.2389 & 0.0958 & 2.49 & \multirow{2}{*}{1.0290} & 1 & -0.2598 & 0.0940 & -2.76 & \multirow{2}{*}{1.0260} \\
\hline & 2 & 0.3301 & 0.0963 & 3.43 & & 2 & -0.3869 & 0.0941 & -4.11 & \\
\hline
\end{tabular}

in Table 8 suggest that the series requires differencing to remove non-stationarity in mean. The estimates of $\rho_{k}$ and $\phi_{k k}$ of the first order differenced series $\left((1-B) X_{t}\right)$ shown in Table 8 , indicates that both $\rho_{k}$ and $\phi_{k k}$ cut off after lag one. This suggests that the pattern in the differenced series may be adequately described by either $\mathrm{AR}(1)$ process or MA(1) process. The estimates ( $\hat{\rho}_{k}$ and $\hat{\phi}_{k k}$ ) of the residuals from the fitted models $(\operatorname{AR}(1)$ and $\mathrm{MA}(1))$ also shown in Table 8, indicate that both models adequately describe the pattern in the series [33]. The estimate $\left(\hat{\phi}_{1}=-0.2369\right)$ of $\phi_{1}$ in the AR(1) process, shown in Table 9 satisfies the stationarity condition, while the estimate $\left(\hat{\theta}_{1}=0.2581\right)$ of $\theta_{1}$ in MA(1) process also shown in Table 9 satisfy the invertibility condition. In addittion, both estimates ( $\hat{\phi}_{1}$ and $\hat{\theta}_{1}$ ) compare favourably well in absolute terms, but with opposite signs. Here again contrary to the widely held duality concept, these indicate that a stationary $\mathrm{AR}(1)$ process can be adequately represented by an invertible $\mathrm{MA}(1)$ process.

The second real life data used to illustrate the breakdown of duality is the monthly All Shares Index of the Nigeria Stock Exchange (NSE), for the period January 1, 1985 to December 31, 2007, collected from the CBN Statistical Bulletin [31] [32] [34]. Following the procedure of [35] [36], the original series was shown to require logarithmic transformation to stabilize its variance. The estimates of $\rho_{k}$ and $\phi_{k k}$ of the transformed series $\left(Y_{t}\right)$ shown in Table 10, suggest that the series requires differencing to remove non-stationarity in mean. The estimates ( $\hat{\rho}_{k}$ and $\hat{\phi}_{k k}$ ) of acf and pacf of the first order differenced series $\left(Z_{t}\right)$ also shown in Table 10, indicate that both $\hat{\rho}_{k}$ and $\hat{\phi}_{k k}$ cut off after lag five. These suggest that the pattern in the series may be adequately described by either AR(5) model or MA(5) model. Both models were fitted to the series and the estimates ( $\hat{\rho}_{k}$ and $\hat{\phi}_{k k}$ ) of acf and pacf of the residuals from the fitted models shown in Table 10, indicate that both models adequately describe the pattern in the series. However, some of the estimates of the parameters of the fitted 
Table 8. The estimates of $\rho_{k}$ and $\phi_{k k}$ of $X_{t},(1-B) X_{t}$ and residuals from the fitted models (AR(1) and MA(1) Models).

\begin{tabular}{|c|c|c|c|c|c|c|c|c|}
\hline \multirow{4}{*}{$k$} & \multicolumn{8}{|c|}{ CFA } \\
\hline & \multirow{2}{*}{\multicolumn{2}{|c|}{$X_{t}$}} & \multirow{2}{*}{\multicolumn{2}{|c|}{$(1-B) X_{t}$}} & \multicolumn{4}{|c|}{ Residuals $\left(e_{t}\right)$} \\
\hline & & & & & \multicolumn{2}{|c|}{$\operatorname{AR}(1)$} & \multicolumn{2}{|c|}{ MA(1) } \\
\hline & $\hat{\rho}_{k}$ & $\hat{\phi}_{k k}$ & $\hat{\rho}_{k}$ & $\hat{\phi}_{k k}$ & $\hat{\rho}_{k}$ & $\hat{\phi}_{k k}$ & $\hat{\rho}_{k}$ & $\hat{\phi}_{k k}$ \\
\hline 1 & 0.94 & 0.94 & -0.25 & -0.25 & -0.03 & -0.03 & -0.01 & -0.01 \\
\hline 2 & 0.90 & 0.13 & -0.05 & -0.11 & -0.09 & -0.09 & -0.03 & -0.03 \\
\hline 3 & 0.86 & 0.03 & 0.08 & 0.04 & 0.07 & 0.06 & 0.06 & 0.06 \\
\hline 4 & 0.82 & -0.05 & -0.04 & -0.01 & -0.03 & -0.04 & -0.03 & -0.03 \\
\hline 5 & 0.78 & -0.01 & -0.02 & -0.03 & -0.02 & -0.01 & -0.02 & -0.02 \\
\hline 6 & 0.74 & 0.01 & 0.04 & 0.02 & 0.02 & 0.01 & 0.02 & 0.01 \\
\hline 7 & 0.71 & 0.04 & -0.07 & -0.06 & -0.07 & -0.07 & -0.07 & -0.07 \\
\hline 8 & 0.68 & 0.07 & 0.01 & -0.02 & -0.01 & -0.01 & -0.01 & -0.01 \\
\hline 9 & 0.66 & 0.00 & 0.00 & -0.01 & 0.00 & -0.02 & -0.01 & -0.02 \\
\hline 10 & 0.63 & -0.02 & -0.03 & -0.03 & -0.04 & -0.04 & -0.05 & -0.05 \\
\hline 11 & 0.61 & -0.02 & -0.03 & -0.05 & -0.07 & -0.08 & -0.08 & -0.09 \\
\hline 12 & 0.59 & 0.00 & -0.12 & -0.16 & -0.15 & -0.17 & -0.16 & -0.18 \\
\hline 13 & 0.57 & 0.06 & -0.02 & -0.10 & -0.07 & -0.10 & -0.09 & -0.10 \\
\hline 14 & 0.55 & 0.04 & -0.08 & -0.16 & -0.10 & -0.15 & -0.12 & -0.15 \\
\hline 15 & 0.54 & 0.06 & -0.02 & -0.10 & -0.04 & -0.08 & -0.05 & -0.07 \\
\hline 16 & 0.54 & 0.02 & 0.00 & -0.07 & 0.00 & -0.06 & -0.01 & -0.05 \\
\hline 17 & 0.53 & -0.01 & 0.01 & -0.03 & -0.01 & -0.04 & 0.00 & -0.03 \\
\hline 18 & 0.52 & -0.02 & -0.08 & -0.12 & -0.05 & -0.10 & -0.04 & -0.08 \\
\hline 19 & 0.51 & 0.06 & 0.14 & 0.06 & 0.16 & 0.11 & 0.16 & 0.11 \\
\hline 20 & 0.49 & -0.06 & 0.08 & 0.12 & 0.10 & 0.09 & 0.11 & 0.10 \\
\hline 21 & 0.47 & -0.09 & -0.08 & -0.02 & -0.04 & -0.02 & -0.03 & -0.03 \\
\hline 22 & 0.45 & -0.01 & 0.13 & 0.10 & 0.11 & 0.10 & 0.12 & 0.08 \\
\hline 23 & 0.42 & -0.08 & -0.06 & -0.04 & -0.04 & -0.08 & -0.04 & -0.09 \\
\hline 24 & 0.39 & -0.01 & -0.02 & -0.06 & -0.04 & -0.07 & -0.04 & -0.08 \\
\hline 25 & 0.36 & -0.03 & -0.01 & -0.13 & -0.03 & -0.14 & -0.02 & -0.13 \\
\hline 26 & 0.35 & 0.09 & -0.03 & -0.13 & 0.00 & -0.08 & 0.01 & -0.07 \\
\hline 27 & 0.34 & 0.10 & 0.13 & 0.06 & 0.15 & 0.11 & 0.15 & 0.11 \\
\hline 28 & 0.31 & -0.22 & 0.07 & 0.09 & 0.09 & 0.06 & 0.09 & 0.06 \\
\hline 29 & 0.28 & -0.01 & -0.11 & -0.04 & -0.09 & -0.06 & -0.08 & -0.06 \\
\hline 30 & 0.26 & 0.01 & 0.06 & 0.01 & 0.04 & 0.03 & 0.04 & 0.03 \\
\hline 31 & 0.24 & 0.00 & 0.01 & 0.05 & 0.01 & 0.05 & 0.00 & 0.05 \\
\hline 32 & 0.22 & -0.04 & -0.06 & 0.01 & -0.07 & 0.00 & -0.07 & 0.00 \\
\hline 33 & 0.20 & 0.02 & -0.01 & 0.00 & -0.04 & 0.00 & -0.04 & 0.00 \\
\hline 34 & 0.18 & 0.02 & -0.04 & 0.00 & -0.04 & 0.00 & -0.05 & 0.00 \\
\hline 35 & 0.18 & 0.03 & 0.01 & 0.01 & 0.01 & 0.01 & 0.00 & 0.00 \\
\hline 36 & 0.18 & 0.06 & & & & & & \\
\hline
\end{tabular}


Table 9. Estimates of parameters of $\mathrm{AR}(1)$ process and $\mathrm{MA}(1)$ process fitted to the monthly average exchange rate of Naira per unit of CFA currency.

\begin{tabular}{|c|c|c|c|c|c|c|c|}
\hline \multicolumn{4}{|c|}{ AR(1) Model } & \multicolumn{4}{|c|}{ MA(1) Model } \\
\hline Coefficient & Estimate & Std Error & t-value & Coefficient & Estimate & Std Error & t-value \\
\hline$\phi_{1}$ & -0.2369 & 0.0816 & -2.90 & $\theta_{1}$ & 0.2581 & 0.0811 & 3.18 \\
\hline$\hat{\sigma}^{2}$ & & 0.0002 & & $\hat{\sigma}^{2}$ & & 0.0002 & \\
\hline
\end{tabular}

Table 10. The estimates of $\rho_{k}$ and $\phi_{k k}$ of $X_{t},(1-B) X_{t}$ and residuals from the fitted models (AR(5) process and MA(5) process).

\begin{tabular}{|c|c|c|c|c|c|c|c|c|}
\hline \multirow{4}{*}{$k$} & \multicolumn{8}{|c|}{ NSE ALL SHARES INDEX } \\
\hline & \multirow{2}{*}{\multicolumn{2}{|c|}{$Y_{t}=\log _{e} X_{t}$}} & \multirow{2}{*}{\multicolumn{2}{|c|}{$Z_{t}=(1-B) Y_{t}$}} & \multicolumn{4}{|c|}{ Residuals $\left(e_{t}\right)$} \\
\hline & & & & & \multicolumn{2}{|c|}{$\mathrm{AR}(5)$} & \multicolumn{2}{|c|}{$\mathrm{MA}(5)$} \\
\hline & $\hat{\rho}_{k}$ & $\hat{\phi}_{k k}$ & $\hat{\rho}_{k}$ & $\hat{\phi}_{k k}$ & $\hat{\rho}_{k}$ & $\hat{\phi}_{k k}$ & $\hat{\rho}_{k}$ & $\hat{\phi}_{k k}$ \\
\hline 1 & 0.99 & 0.99 & 0.19 & 0.19 & 0.00 & 0.00 & 0.00 & 0.00 \\
\hline 2 & 0.98 & -0.01 & 0.15 & 0.12 & 0.01 & 0.01 & -0.01 & -0.01 \\
\hline 3 & 0.97 & 0.00 & 0.06 & 0.01 & -0.02 & -0.02 & 0.02 & 0.02 \\
\hline 4 & 0.96 & -0.01 & -0.02 & -0.06 & 0.00 & 0.00 & 0.00 & 0.00 \\
\hline 5 & 0.95 & -0.01 & 0.18 & 0.19 & 0.01 & 0.01 & 0.01 & 0.01 \\
\hline 6 & 0.93 & -0.03 & 0.04 & -0.02 & -0.01 & -0.01 & 0.03 & 0.03 \\
\hline 7 & 0.92 & -0.01 & 0.02 & -0.04 & -0.05 & -0.05 & -0.01 & -0.01 \\
\hline 8 & 0.91 & -0.01 & 0.08 & 0.08 & 0.07 & 0.07 & 0.08 & 0.08 \\
\hline 9 & 0.90 & -0.01 & 0.05 & 0.05 & 0.04 & 0.04 & 0.02 & 0.02 \\
\hline 10 & 0.89 & 0.00 & 0.06 & -0.01 & 0.02 & 0.02 & 0.05 & 0.05 \\
\hline 11 & 0.88 & 0.00 & -0.01 & -0.04 & -0.03 & -0.03 & -0.03 & -0.03 \\
\hline 12 & 0.87 & 0.01 & -0.03 & -0.02 & -0.02 & -0.01 & -0.01 & -0.01 \\
\hline 13 & 0.86 & 0.01 & -0.08 & -0.10 & -0.12 & -0.12 & -0.10 & -0.11 \\
\hline 14 & 0.84 & 0.00 & 0.04 & 0.07 & 0.03 & 0.02 & 0.03 & 0.02 \\
\hline 15 & 0.83 & -0.01 & 0.04 & 0.04 & 0.01 & 0.02 & 0.02 & 0.01 \\
\hline 16 & 0.82 & -0.01 & 0.10 & 0.08 & 0.11 & 0.11 & 0.11 & 0.11 \\
\hline 17 & 0.81 & -0.02 & 0.02 & -0.03 & -0.01 & -0.02 & -0.01 & -0.02 \\
\hline 18 & 0.80 & 0.02 & 0.02 & 0.03 & 0.02 & 0.01 & 0.01 & 0.00 \\
\hline 19 & 0.79 & 0.00 & 0.07 & 0.05 & 0.07 & 0.07 & 0.06 & 0.06 \\
\hline 20 & 0.78 & 0.00 & 0.08 & 0.05 & 0.10 & 0.10 & 0.09 & 0.10 \\
\hline 21 & 0.77 & 0.00 & -0.02 & -0.09 & -0.05 & -0.03 & -0.05 & -0.04 \\
\hline 22 & 0.76 & 0.00 & -0.03 & -0.02 & 0.00 & 0.01 & 0.00 & -0.01 \\
\hline 23 & 0.75 & -0.01 & -0.07 & -0.05 & -0.04 & -0.03 & -0.04 & -0.04 \\
\hline 24 & 0.74 & -0.01 & -0.09 & -0.11 & -0.04 & -0.07 & -0.04 & -0.07 \\
\hline 25 & 0.73 & -0.01 & -0.11 & -0.13 & -0.10 & -0.12 & -0.10 & -0.12 \\
\hline 26 & 0.72 & -0.01 & -0.10 & -0.04 & -0.07 & -0.08 & -0.05 & -0.08 \\
\hline
\end{tabular}




\section{Continued}

\begin{tabular}{|c|c|c|c|c|c|c|c|c|}
\hline 27 & 0.71 & -0.02 & -0.13 & -0.08 & -0.10 & -0.10 & -0.10 & -0.10 \\
\hline 28 & 0.70 & 0.00 & -0.06 & 0.00 & 0.01 & -0.02 & 0.00 & -0.02 \\
\hline 29 & 0.69 & 0.00 & -0.11 & -0.05 & -0.10 & -0.09 & -0.10 & -0.08 \\
\hline 30 & 0.68 & 0.04 & -0.03 & 0.04 & 0.00 & -0.01 & 0.01 & 0.01 \\
\hline 31 & 0.67 & -0.01 & 0.02 & 0.08 & 0.03 & 0.04 & 0.02 & 0.05 \\
\hline 32 & 0.66 & -0.01 & -0.02 & 0.04 & 0.02 & 0.04 & 0.01 & 0.04 \\
\hline 33 & 0.65 & -0.01 & -0.04 & -0.02 & -0.03 & 0.01 & -0.03 & 0.02 \\
\hline 34 & 0.63 & -0.04 & -0.02 & 0.01 & 0.00 & 0.00 & -0.01 & 0.01 \\
\hline 35 & 0.62 & 0.01 & -0.03 & -0.01 & -0.05 & -0.05 & -0.06 & -0.05 \\
\hline 36 & 0.61 & -0.02 & 0.11 & 0.10 & 0.14 & 0.11 & 0.13 & 0.12 \\
\hline 37 & 0.60 & -0.02 & 0.03 & 0.00 & 0.03 & 0.05 & 0.03 & 0.05 \\
\hline 38 & 0.59 & -0.01 & -0.02 & -0.07 & -0.02 & -0.05 & -0.03 & -0.05 \\
\hline 39 & 0.58 & -0.01 & -0.04 & -0.06 & -0.04 & -0.07 & -0.05 & -0.08 \\
\hline 40 & 0.57 & 0.00 & 0.00 & 0.04 & 0.04 & 0.02 & 0.04 & 0.02 \\
\hline 41 & 0.56 & -0.02 & -0.01 & -0.01 & -0.02 & 0.01 & -0.02 & 0.01 \\
\hline 42 & 0.54 & -0.03 & -0.03 & -0.04 & -0.03 & -0.04 & -0.04 & -0.04 \\
\hline 43 & 0.53 & -0.02 & -0.06 & 0.01 & -0.04 & 0.02 & -0.04 & 0.00 \\
\hline 44 & 0.52 & 0.00 & -0.04 & 0.03 & -0.01 & 0.03 & 0.00 & 0.02 \\
\hline 45 & 0.51 & 0.00 & -0.05 & -0.02 & -0.05 & -0.02 & -0.05 & -0.01 \\
\hline 46 & 0.50 & 0.01 & -0.02 & -0.02 & -0.02 & -0.02 & -0.01 & -0.02 \\
\hline 47 & 0.48 & -0.02 & 0.01 & 0.05 & 0.03 & 0.05 & 0.03 & 0.04 \\
\hline 48 & 0.47 & 0.00 & -0.04 & -0.05 & -0.01 & -0.01 & -0.01 & -0.02 \\
\hline 49 & 0.46 & 0.01 & -0.08 & -0.08 & -0.08 & -0.06 & -0.09 & -0.06 \\
\hline 50 & 0.45 & 0.00 & 0.00 & -0.01 & 0.01 & -0.03 & 0.01 & -0.04 \\
\hline 51 & 0.44 & -0.01 & 0.03 & 0.01 & 0.04 & 0.01 & 0.03 & 0.00 \\
\hline 52 & 0.43 & 0.01 & 0.06 & -0.02 & 0.09 & 0.01 & 0.08 & 0.02 \\
\hline 53 & 0.42 & -0.01 & -0.03 & -0.06 & -0.03 & -0.05 & -0.03 & -0.05 \\
\hline 54 & 0.41 & 0.00 & -0.05 & -0.05 & -0.05 & -0.06 & -0.05 & -0.06 \\
\hline 55 & 0.40 & -0.01 & -0.05 & -0.05 & -0.03 & -0.07 & -0.03 & -0.06 \\
\hline 56 & 0.38 & 0.00 & -0.01 & -0.02 & 0.03 & -0.04 & 0.02 & -0.03 \\
\hline 57 & 0.37 & -0.01 & -0.06 & -0.03 & -0.07 & -0.06 & -0.08 & -0.06 \\
\hline 58 & 0.36 & 0.00 & -0.03 & 0.03 & -0.03 & -0.01 & -0.02 & -0.01 \\
\hline 59 & 0.35 & -0.01 & 0.00 & 0.05 & 0.02 & 0.03 & 0.02 & 0.04 \\
\hline 60 & 0.34 & 0.00 & 0.02 & 0.05 & 0.03 & 0.03 & 0.03 & 0.03 \\
\hline 61 & 0.33 & 0.01 & 0.03 & 0.05 & 0.01 & 0.05 & 0.01 & 0.05 \\
\hline 62 & 0.32 & 0.00 & 0.03 & 0.06 & 0.04 & 0.07 & 0.04 & 0.07 \\
\hline
\end{tabular}

models shown in Table 11 are not significant. Therefore, the subset models were fitted to the series following the selection of subset time series models by [37] 
Table 11. Estimates of parameters of AR(5) model and MA(5) model fitted to the monthly all shares index of the Nigeria Stock Exchange (NSE).

\begin{tabular}{cccccccc}
\hline \multicolumn{3}{c}{$\operatorname{AR}(5)$} & \multicolumn{5}{c}{$\operatorname{MA}(5)$} \\
\hline Coefficient & Estimate & Std Error & t-value & Coefficient & Estimate & Std Error & t-value \\
\hline $\begin{array}{c}\text { Constant } \\
\phi_{0}\end{array}$ & 0.0136 & 0.0029 & 4.75 & $\theta_{0}$ & 0.0228 & 0.0042 & 5.42 \\
$\phi_{1}$ & 0.1745 & 0.0599 & 2.91 & $\theta_{1}$ & -0.1741 & 0.0602 & -2.89 \\
$\phi_{2}$ & 0.1220 & 0.0607 & 2.01 & $\theta_{2}$ & -0.1756 & 0.0612 & -2.87 \\
$\phi_{3}$ & -0.0015 & 0.0612 & -0.02 & $\theta_{3}$ & -0.0156 & 0.0621 & -0.25 \\
$\phi_{4}$ & -0.0895 & 0.0607 & -1.47 & $\theta_{4}$ & 0.0656 & 0.0612 & 1.07 \\
$\phi_{5}$ & 0.1965 & 0.0603 & 3.26 & $\theta_{5}$ & -0.1711 & 0.0606 & -2.82 \\
$\hat{\sigma}^{2}$ & & 0.0022 & & $\hat{\sigma}^{2}$ & & 0.0022 & \\
\hline
\end{tabular}

Table 12. Estimates of parameters of subset AR(5) model and subset MA(5) model for the models fitted to the monthly all shares index of the Nigeria Stock Exchange (NSE).

\begin{tabular}{|c|c|c|c|c|c|c|c|}
\hline \multicolumn{4}{|c|}{ AR(5) SUBSET } & \multicolumn{4}{|c|}{ MA(5) SUBSET } \\
\hline Coefficient & Estimate & Std Error & $\mathrm{t}$-value & Coefficient & Estimate & Std Error & t-value \\
\hline Constant & & & & Constant & & & \\
\hline$\phi_{0}$ & 0.0126 & 0.0036 & 3.47 & $\theta_{0}$ & 0.0202 & 0.0038 & 5.31 \\
\hline$\phi_{1}$ & 0.1697 & 0.0599 & 2.83 & $\theta_{1}$ & -0.1648 & 0.0404 & -4.07 \\
\hline$\phi_{2}$ & 0.1092 & 0.0602 & 1.82 & $\theta_{2}$ & -0.1793 & 0.0454 & -3.95 \\
\hline$\phi_{5}$ & 0.1801 & 0.0594 & 3.03 & $\theta_{5}$ & -0.1774 & 0.0388 & -4.57 \\
\hline$\hat{\sigma}^{2}$ & & 0.0022 & & $\hat{\sigma}^{2}$ & & 0.0022 & \\
\hline
\end{tabular}

and the non-linear least squares method of estimation of parameters by [38]. The estimates of the parameters of the subset AR(5) model and the subset MA(5) model shown in Table 12 compare favourably well in absolute terms with opposite signs. Contrary to the widely held duality concept, these indicate that an $\mathrm{AR}(5)$ series can be adequately represented by an MA(5) model and conversely.

\section{Conclusions}

In summary, this study has demonstrated analytically and empirically that the concept of duality that a finite order stationary autoregressive process of order $p$ $(\operatorname{AR}(p))$ stationary is equivalent to an infinite order moving average (MA) process and invertible moving average of order $q(\mathrm{MA}(q))$ is equivalent to an infinite order autoregressive (AR) process is not universally true. Specifically, this study constructed regions of breakdown of duality starting from $\operatorname{AR}(p)$ to $\operatorname{MA}(p)$ processes and from $\operatorname{MA}(p)$ to $\operatorname{AR}(p)$ processes for $p=1,2$. These regions, designated as "Non-duality" regions in this study, have been illustrated mathematically and graphically. In these regions (a) both the Autocorrelation function and the Partial Autocorrelation function of the AR process and MA process cuts off 
after equal lags (b) a finite AR model can be adequately represented by a finite MA model of equal order and conversely with the same error variance and (c) negative values of the parameters of the AR process are mapped into positive values of the parameters of the equivalent MA process and conversely.

In view of these, it has been recommended that the concept of duality should be treated with caution in analysis of time series data.

\section{Conflicts of Interest}

The authors declare no conflicts of interest regarding the publication of this paper.

\section{References}

[1] Atiyah, M.E. (2007) Duality in Mathematics and Physics. Conference Lecture at Institut de Mathematica de la Universidad de Barcelona (IMUB), Barcelona, 69-91. http://www.imub.ub.es

[2] Jorgen, T. (2001) Duality Theory. http://www.math.ku.dk/ tind/duality.pdf

[3] Narry, F.S. (1997) The Paradox of Authority and Servanthood in the Gospel of Mark. Bibliotheca Sacra, 154, 452-460.

[4] Burns, D.M. (1974) Language, Thought and Logical Paradoxes. Buldhist Publication Society, Kandy.

[5] Giantbomb (2016) Duality. https://www.giantbomb.com/duality/3015-210

[6] Cantini, A. (2014) Paradoxes and Contemporary Logic. The Stanford Encyclopedia of Philosophy Archive (Fall 2014 Edition). http://plato.stanford.edu/archives/fall2014/entries/paradoxes-contemporary-logic/

[7] Encycyclopedia Britannica Online (2000) Duality. http://www.eb.com

[8] Kleiner, I. and Movshovitz-Hadar, N. (1994) The Role of Paradoxes in the Evolution of Mathematics. American Mathematical Monthly, 101, 963-974. https://doi.org/10.1080/00029890.1994.12004576

[9] Metcalfe, M. (2005) Generalisation: Learning across Epistemologies. Forum for Qualitative Research, 6, 1-10.

[10] Nancy, C.M., David, H.B. and Lee, N. (2006) Paradox and Transformation. World Indigenous Nations Higher Education Consortium Journal, 2, 13-31

[11] Oxford Dictionaries (2016) Duality. Oxford University Press, Britain. http://www.oxforddictionaries.com

[12] Philip, L.G. (2016) Duality. Roget's 21st Century Thesaurus, 3rd Edition. http://www.dictionary.com/browse/duality

[13] Swart, J.M. (2013) Duality and Intertwining of Markov Chain. A Lecture Note in Europe School, CIRM, Limmy (Marseille), France.

[14] Cucic, D.A. (2008) Paradox in Physics, the Consistency of Inconsistency (Long Version). http://www.arxiv.org/pdf/0812.2541

[15] Accounting-Simplified (2016) Dual Aspect Concept: Duality Principle in Accounting.

http://accounting-simplified.com/financial/concepts-andprinciples/duality.html\#de finition

[16] Augusztinovics, M. (1997) Accounting for Duality and Circularity. In Simonovits A. 
and Steenge, A.E., Eds., Prices, Growth and Cycles, Palgrave Macmillan Press Ltd., London, 1-18. https://doi.org/10.1007/978-1-349-25275-6_1

[17] Wei, W.W.S. (1989) Time Series Analysis: Univariate and Multivariate Methods. Addison-Wesley Publishing Company Inc., California.

[18] Andres, M.A. and Carolina, G.M. (2012) Lecture Note on Time Series Analysis: Autoregressive, Moving Average and ARMA Processes. Universidad Carlos III de Madrid and Universidad Politecnica de Madrid, Madrid.

[19] Bo, S. (2011) Lectures in Modern Economic Time Series Analysis. 2nd Edition, Linköping University, Linköping.

[20] Box, G.E.P., Jenkins, G.M. and Reinsel, G.C. (1994) Time Series Analysis: Forcasting and Control. 3rd Edition, John Wiley and Sons Inc. Publication, Hoboken.

[21] Brockwell, P.J. and Davis, R.A. (1991) Time Series: Theory and Methods. Springer, New York. https://doi.org/10.1007/978-1-4419-0320-4

[22] Chatfield, C. (2004) The Analysis of Time Series: An Introduction. Chapman and Hall/CRC Press, Boca Raton.

[23] John, F. (1999) Lecture Note on Univariate Time Series Analysis and Box Jenkings Forecasting. Trinity College, Dublin.

https://www.tcd.ie/Economics/staff/frainj/main/MSc\%20Material/TimeSeriesAnaly sis/UNIVAR4.PDF

[24] Mcleod, A.I. (1984) Duality and Other Properties of Multiplicative Seasonal Autoregressive Moving Average Models. Biometrika, 71, 207-211.

[25] Michael, L. (2014) Basic Time Series Models. A Lecture Note of Purdue University. http://www.stat.purdue.edu/ mlevins/stat420

[26] Rafal, W. (2007) Modeling and Forecasting Electricity Loads and Prices: A Statistical Approach. John Wiley and Sons Inc. Publication, Hoboken, New Jersey.

[27] Robert, M.K. (2011) Lecture Note on Applied Time Series Analysis. University of Vienna and Institute for Advanced Studies, Vienna. Robert.kunst@univie.ac.at

[28] David, A.P. (1970) A Duality between Autoregressive and Moving Average Processes Concerning their Least Square Parameter Estimates. The Annals of Mathematical Statistics, 41, 722-726. https://doi.org/10.1214/aoms/1177697081

[29] Nghi, H.N. and Wendy, L. (2009) New Methods for Solving Quadratic Equations and Inequalities. Revised Edition, Trafford Publishing, Blommington.

[30] Tuckwell, H.C. (1988) Elementary Applications of Probability Theory. Chapman and Hall, London. https://doi.org/10.1201/9780203758564

[31] CBN (Central Bank of Nigeria) (2013). https://www.cbn.gov.ng/rates/exrate.asp?year=2013

[32] CBN (Central Bank of Nigeria) (2014) Statistical Bulletin. Vol. 25. http://www.cbnbank.org

[33] Box, G.E.P. and Pierce, D.A. (1970) Distribution of Residual Autocorrelations in Autoregressive-Integrated Moving Average Time Series Models. Journal of the American Statistical Association, 65, 1509-1526.

[34] Nigerian Stock Exchange(2014) The All Share Index. http://www.nse.com.ng

[35] Akpanta, A.C. and Iwueze, I, S. (2009) On Applying the Bartlett Transformation Method to Time Series Data. Journal of Mathematical Sciences, 20, 227-243.

[36] Iwueze, I.S. and Akpanta, A.C. (2007) Effect of the Logarithmic Transformation on the Trend-Cycle Component. Journal of Applied Sciences, 7, 2414-2422

https://doi.org/10.3923/jas.2007.2414.2422 
[37] Haggan, V. and Oyetunji, O.B. (1984) On the Selection of Subset Autoregressive Time Series Models. Journal of Time Series Analysis, 5, 103-113.

https://doi.org/10.1111/j.1467-9892.1984.tb00380.x

[38] Donald, W.M. (1963) An Algorithm for Least Squares Estimation of Non Linear Parameter. Journal of the Society for Industrial and Applied Mathematics, 11, 431-441. 